\title{
A Study on the Improvement of College Students' English Cultural Accomplishment under the Concept of General Education
}

\author{
Xunfeng Yin \\ TaiShan University, Tai'an, Shandong, 271000, China
}

\begin{abstract}
Besides imparting knowledge, college English course is also a language carrier for students to understand western culture and a way to improve their comprehensive cultural literacy. Therefore, under the guidance of General Education theory, this paper attempts to integrate the appreciation of English literary translations into College English teaching, so that non-English majors can improve their English language ability, at the same time, they can improve their critical appreciation ability and cultural accomplishment.
\end{abstract}

Index Terms - general education, polysystem theory, cultural accomplishment

\section{RESEARCH BACKGROUND}

In order to adapt to the new situation of the development of higher education in China, deepen the reform of teaching, improve the quality of teaching, and meet the needs of the state and society for the cultivation of talents in the new era, in July 2007, the Ministry of Education promulgated the requirements for College English Curriculum Teaching (trial), which states: "College English teaching is a teaching system that combines a variety of teaching modes and teaching methods, which is guided by foreign language teaching theory, with English language knowledge and skills, crosscultural communication and learning strategies as the main content." As is stated, the teaching goal of college English is to cultivate students' comprehensive English application ability, especially their listening and speaking ability, so that they can communicate oral and written information effectively in English in their future work and social communication. At the same time, their autonomous learning ability and their comprehensive cultural accomplishment should also be strengthened in order to meet the needs of China's economic development and international exchanges.

Therefore, college English course is not only a basic language knowledge course, but also a general education course including English knowledge, language expression skills, language application and multicultural knowledge, which is the language carrier for students to understand western culture, and a way to improve students' comprehensive cultural accomplishment. However, most of the current college English teaching mainly focuses on the teaching of basic language knowledge, and the teaching reform also focuses on the cultivation of the ability of comprehensive use of English, especially the cultivation of listening and speaking ability. There has been a lack of research on improving students' comprehensive cultural accomplishment.

So, this paper intends to take reading English literary classics as the cutting point to improve students' ability of comprehensive use of English while improving their comprehensive cultural accomplishment, and explore a new way of college English teaching under the concept of General Education. At present, there are three problems in reading English literary masterpieces for non-English majors.

Firstly, there is the biased understanding of reading English literary classics, that is, non-English major college students generally have a view that it is necessary for English majors to read English literary classics, as it is the requirement for them to improve their English level; and non-English majors only need to pass the final exam of each semester. Consequently, their reading purposes in their spare time are very different, just for entertainment, thus many students choose "fast food culture" or some "online literature". Under this kind of cognition, it is difficult to take this as the starting point. Therefore, the first thing that needs to be solved is that they are biased in their cognition of reading English literary classics.

Secondly, there is the problem of improper methods and lack of guidance in reading English literary classics. For non-English major students who choose to read English literary classics, they are limited by their English proficiency in such reading. There will be many difficulties, such as: a large number of new words, complex sentence patterns, lengthy narration, and limited understanding ability etc. To make it worse, the lack of teachers' guidance in reading makes it difficult for them to improve their reading speed, depth, time, and number of readings, and even make the readers give up halfway.

Thirdly, there is the problem of too many versions of translated English literary classics, which makes it difficult for students to make a choice. Most of the non-English major college students who choose to read English literary classics choose to read the translated versions, which were different in different periods. Moreover, when reading, they know little about the linguistic features of the target text, the political, economic, cultural and other aspects reflected in the 
works at that time, as well as the influence of the background of the different translators in the translation on the target text. This kind of reading only increases the number of works that students read, which is of little benefit to the improvement of their English reading ability, and even less to the understanding of western culture and the improvement of their comprehensive cultural accomplishment.

Thus it can be seen that it is necessary to rely on the concept of General Education to improve the basic English language skills, comprehensive application ability and multicultural appreciation ability of college students, and to promote the realization of college English classroom teaching objectives. This paper makes a comparative reading of English translated literary classics and integrates the appreciation of English literary translation works into college English classroom teaching.

\section{GENERAL EDUCATION}

\section{A. Research of General Education Abroad}

General Education originated in the 19th century. At that time, many European and American scholars felt that the academic branches of modern universities were too specialized and their knowledge was seriously separated, so they created general education in order to train students to think independently, have some understanding of different disciplines and integrate different knowledge, so that the ultimate goal to cultivate complete people could be realized. In 1829, A. S. Packard in the United States defended the general courses of the university curriculum, including classical Chinese, literature, and science, as a prerequisite for professional learning, arguing that students had to take these public courses to get the necessary co-training, and this kind of education was called General Education. Since he first linked general education with university education, General Education practice has emerged in Europe and the United States

According to Huang Kunjin (2006, p251), the goal of General Education in the United States is to make the individual develop healthily, including the promotion of the purpose of life, the extraction of responses to emotions, and the use of the best contemporary knowledge to fully understand the nature of various things. Thus it can be seen that General Education will increase the breadth and depth of students' knowledge, expand students' vision, make students possess both humanistic literacy and scientific literacy, and train students into all-round people.

\section{B. Domestic Research Status of General Education}

Compared with the United States, General Education in the modern sense of China started late, but the concept of General Education has a long history and has a certain ideological and practical basis. In the Dictionary of Education edited by Gu Mingyuan, president of Chinese Educational Association, General Education is expounded as a kind of educational thought about the purpose and content of education in modern times and the education is carried out accordingly $(\mathrm{Gu}, 1998)$. In the stage of higher education, it refers to the education of common content that college students should receive. The teaching goal of college English promulgated by the Ministry of Education of China is to cultivate students' comprehensive English application ability, especially their listening and speaking ability, at the same time to enhance their autonomous learning ability and improve their comprehensive cultural accomplishment in order to meet the needs of China's economic development and international exchanges. So college English curriculum is consistent with the concept of General Education in terms of the discipline's nature, teaching objectives and educational content.

Therefore, Chinese scholars have also put forward the concept of foreign language General Education. For example, Wang Shouren (2011) believes that the English course of General Education is aimed at realizing the requirements of improving comprehensive cultural accomplishment, including students' critical thinking and intercultural communicative competence. Moreover, many Chinese scholars have also discussed and studied how to reform the English teaching mode under the concept of General Education, how to carry out the curriculum, the professional development of teachers, and the cultivation of talents and so on. Among them, some scholars, such as Zhu Xi (2011), have discussed the role of reading English literary classics in improving the comprehensive humanistic literacy of college students, but this kind of study is aimed at English majors instead of non-English majors.

Consequently, this paper intends to take non-English major college students as the research object, take reading English literary masterpieces as the starting point, and explore the role of literary classics reading in improving students' comprehensive cultural accomplishment under the concept of General Education.

\section{The Relevant Information About the Study on the Improvement of College Students’ EngLish CUltural ACCOMPlishment UNDER THE CONCEPT OF GENERAL EDUCATION}

\section{A. Theoretical Basis of the Study}

The study is based on the concept of General Education and guided by polysystem theory, the theory put forward by Itamar Even-Zohar, an Israeli scholar, to explain the behavior and evolution of literary systems. (Baker, 2001). As a theory which plays a guiding role in understanding the nature of translation and in carrying out translation criticism, polysystem theory can be used to guide students to analyze and evaluate different versions of English literary classics in different periods, to improve their ability of English translation and reading in the process of analyzing the original text 
and the target text, to improve the students' multicultural consciousness and realize the teaching goal of cultivating students comprehensive English application ability and improving their comprehensive cultural accomplishment.

\section{B. Subjects of the Study}

In this study, ninety students, majoring in international finance and trade, from Taishan University in Shandong province, China, are chosen to be the subjects of research. During the one year teaching practice, forty-five of the chosen students constitute the experimental class and another forty-five belong to the contrasting class.

\section{Objectives of the Study}

(1) Try to strengthen students' comprehensive cultural accomplishment and achieve teaching objectives. Through comparative reading of English literary masterpieces, non-English majors' critical thinking ability, reading ability and translation ability would be improved; through appreciating and evaluating different translations of English masterpieces in different periods, their multicultural awareness and their multicultural literacy would be enhanced.

(2) Try to promote the renewal of teaching methods and combine language teaching with culture teaching. Through combining non-English majors' reading of English literary translations with college English teaching and combining language teaching with culture teaching, students' comprehensive language ability and students' understanding of different cultures would be improved, and thus form a new college English teaching method and mode.

\section{Methods of the Study}

(1) Questionnaire survey and English reading ability test: Understanding the current situation of non-English majors' reading English translated literary works, the existing difficulties and the basis for choosing different translations; Evaluating their basic linguistic competence, including translation and reading level, thereby establishing practical teaching plans and teaching methods of translation theory;

(2) Literature and theoretical analysis: consulting, analyzing and summarizing the relevant theories of General Education concept and relevant translation theory; selecting experimental materials;

(3) Experimental method: The experimental class and the contrasting class are set up in the teaching. According to the results of the pre-test analysis, the teaching plan of the experimental class is formulated and implemented. After the training, the post-test is implemented. Compare the changes of students in the experimental class and the contrasting class after the implementation of the plan, understand the effect of teaching implementation, write a summary and make the conclusion.

\section{THE PROCESS OF THE STUDY}

This study made an empirical study on the role of literary classics reading in improving students' comprehensive cultural accomplishment under the concept of General Education. Before the beginning of the research, the research object, the teaching plan and the evaluation of the teaching effect were discussed and determined.

The experimenting began in the fall semester of 2017 and lasted one and half years, including about 80 days of winter vacation and summer vacation. The study was carried out in the following three stages:

\section{A. Pre-preparation Phase}

The first stage was the pre-preparatory phase, which lasted about three months, from October to December 2017. Before the study, the selected students were tested and the results showed that there were some differences in vocabulary and grammar level between the two classes, but the differences were not very obvious. After testing, the vocabulary of the students was found to be ranged from about 2500 to 3500 words, which belonged to the middle and upper level in the university.

Firstly, through collective discussion and questionnaire survey, the students in these two classes were investigated. The survey included reading purposes, reading quantity, reading time, reading methods and difficulties in reading, so as to understand students' specific problems in reading English literary masterpieces.

From the discussion, the students of the two classes reported that that most of them would not choose to read English translated literary masterpieces in their spare time if there were no reading tasks assigned by teachers. If they were assigned the reading tasks, most of the students would choose to borrow from the library without consulting the publishing house, the publishing time or the translator. Questionnaire results indicated that the selected students in science classes were rather casual in choosing translated literary works in English. 85\% of the students chose the translated works just because they have "heard" or "seen movies of the same name". However, when it comes to evaluating the language and content of translated literary works and the influence of their times on the translation of literary works, the students in both classes chose either "not caring about the era in which the translator lives, and think that it has no effect on translated literary works" or "never considered this issue".

Secondly, students' English proficiency was tested by written test, which involved vocabulary, reading comprehension and translation. To test students' English reading ability, the test covered the comparison of the original English literary works and the translations of different versions for the sake of understanding of students' reading level and the determination of teaching methods. The tests made it clear that the selected students' language proficiency was relatively weak, and most of them could not tell the differences among varying translated versions. 


\section{B. The Phase of Teaching Operation}

Based on the above phase, it was determined that during the course of College English teaching, the experimental class would integrate the reading of translations of English literary masterpieces; while the contrasting class would adopt the traditional teaching mode. New Horizon College English published by Foreign Language Teaching and Research Press was used as teaching material.

The phase of teaching operation started from February 2018 to December 2018, with one summer vacation accounting for about fifty days. The first semester of 2018 academic year commenced from February to June 2018, and the second semester was from September to December 2018. At the beginning of every semester, the students in the experimental class were given specific instructions on the contents of the first and second semesters and the assessment criteria for the final grades, so that the students fully understood the requirements and process of the course learning.

(1) The first semester:

The first semester's teaching contents included the conventional curriculum teaching and the teaching of polysystem theory. With the help of the study of the first stage, it was known that the students even have never heard of polysystem theory and most of the teaching materials given to the students were in the original English. Therefore, it was expected that students would have some difficulties in accepting the theory. In order to ensure the mastery of the theory, most of the students were interviewed and some were given individual instruction during the extracurricular time.

The explanation of polysystem theory was carried out through collective teaching, and the major contents were arranged as follows:

Chapter one: The theory of polysystem theory and Russian Formalism, mainly explaining Russian Formalism as its source.

Chapter two: Evan-Zohar's hypothesis of polysystem, mainly explaining the literary system, the dynamic stratification of the literary system, and the position of translated literature within the system.

Chapter three: The paradigm of translation studies within polysystem theory, mainly dealing with the translation studies of the target text orientation and Toury's descriptive translation studies.

Chapter Four: The contribution of polysystem theory, mainly explaining translation norms and theme awareness, translation orientation and text orientation.

Chapter Five: The influence of polysystem theory in China, mainly explaining the application of the theory in translation studies in China.

When teaching polysystem theory, students in the experimental class were divided into nine groups and were handed out handouts before class, so that student had the time to preview and find the difficulties by discussing with each other. Before class teaching, the teacher first answered students' questions, get the idea of students' mastery of the theory, and focused on explaining the difficult points accordingly. After class, students were tracked through homework and testing to help them review what they have learned.

(2) The second semester:

The second semester's teaching combined regular course teaching with comparative reading of different translations of literary classics together. Take Gone with the Wind, written by Margaret Mitchell, as the original text for comparative reading and the translated versions of Fu Donghua, Huang Huairen and Zhu Youruo as the comparative reading text, ten chapters of which were selected to be analyzed in terms of the translations of names, literary allusions, long and difficult sentences, the choice of language style together with the differences between complete translation and partial translation. Therefore, under the guidance of polysystem theory, the translation principles of different translations were analyzed, the cultural background of the original author was understood, and the translations influenced by the translator's own cultural background were realized, so as to cultivate students' tolerance to different cultures and improve their comprehensive cultural accomplishment.

When reading different translations of English literary masterpieces, the selected chapters were distributed to each group before class, and the students translated the group's task together through discussion. Before analyzing the translations in each class, different groups analyzed the sentence structure of the original English text and gave their own translations, and then the teacher gave the translations of different translators to help students figure out the translation strategies and work out the reasons for the choice of the strategy, finally the best translation among the groups were selected out. After class, the best translation was sent to every group for them to appreciate for consolidation.

After finishing the guided comparative reading of the chosen chapters of translation works, students of each group were required to choose the translated literary works independently, then find two different translators' versions, and use the translation theory to analyze.

(3) The final grade evaluation included: $60 \%$ of the final paper grade $+40 \%$ of the usual performance (10\% of class attendance, $5 \%$ of pre-class preparation, $15 \%$ of class performance, $10 \%$ of homework).

\section{The Feedback Phase of the Study}

The third phase lasted for three months, from February 2019 to April 2019, and aimed to find out whether the students in the experimental class have improved their level of appreciation of English literary works. After one academic year's teaching operation, the questionnaires mainly focused on such questions as "what is the role of 
polysystem theory in College English teaching", "what is the role of polysystem theory in selecting English translation literary masterpieces", "whether translation theory plays a guiding role in appreciating and analyzing English translation literary masterpieces", and "whether reading English translation literary masterpieces improves students' cultural accomplishment", etc.

Besides, college English proficiency tests as the previous ones in the pre-preparation phase were used to test the experimental class and the contrasting class respectively, and data were collected to make a comprehensive comparative analysis of the learning effect and to compare whether the teaching effect of the experimental class was better than that of the contrasting class.

\section{ANALYSIS AND CONCLUSIONS OF THE STUdY}

Firstly, the study in the first phase indicated that there are many problems in reading English translated literary masterpieces for college students: passive reading of English translated literary masterpieces, lack of guidance during the process, and the lack of relevant translation theory. Therefore, this stage of study has proved that this study is necessary for non-English majors in universities.

Secondly, in the phase of teaching operation, a large number of reading analysis reports was collected. Through the analysis of these reports, it was found that $88 \%$ of the students in the experimental class can master what they have learned after teaching as well as the practice of comparative analysis of translated works, even though students had not been exposed to polysystem theory before; through questionnaire and group discussion, most of the students thought it is acceptable to integrate translation theory into college English teaching.

Thirdly, through the practice of the analysis of translated literary works, it was revealed that the students of the experimental class have made great progress in language competence, which was mainly reflected in the reading, analyzing and translating of the original English text. At the same time, through the analysis of the historical background of the author and translator of the works, they had a better understanding of Chinese culture and Western literature and culture, and enhanced their cross-cultural and multi-cultural awareness.

In the course of this study, the students in the contrasting class have made no improvement in choosing and evaluating translated works, and their linguistic competence and cultural accomplishment have also stagnated without much progress, which proves the necessity of this study from the opposite side.

\section{REFLECTIONS AND PROSPECTS FOR FOLLOW-UP STUDY}

This study justified that through comparative reading of English literary classics, students' language ability, critical thinking ability, multicultural awareness and cultural accomplishment were improved under the guidance of translation theory. However, in the process of implementation, there also occurred three problems.

To begin with, in interviews and questionnaires, 13 of the students (28\% of the total) mentioned that the introduction of polysystem theory into the appreciation of English translated literary masterpieces would lead to the excessive use of analytical and critical consciousness, which may lead to the loss of the significance of appreciating translated literary masterpieces. Over-enhancement of students' awareness of analysis and criticism makes it less significant to appreciate translated literary masterpieces.

Furthermore, although $56 \%$ of the students agree that translation theory should be used to guide students to appreciate English translation literary masterpieces, improve their cultural accomplishment and introduce it into college English teaching for non-English majors, there are still 16\% of the students who still think that polysystem theory is too obscure to understand and can not play an effective guiding role in analyzing and appreciating English translation literary works.

Finally, there occurs the third problem that the students only use their knowledge consciously when they translate and analyze passages in intensive reading classes. There is little difference between the performance of the students in listening and speaking classes. Therefore, the improvement of the students' cultural accomplishment still has a long way to go, and the study will be a long-term process and requires further improvement.

\section{REFERENCES}

[1] Baker, Mona. (2001). Routledge Encyclopedia of Translation Studies. London and New York: Routledge.

[2] Gu Mingyuan. (1998). Dictionary of Education. Shanghai: Shanghai Educational Publishing House.

[3] Huang Kunjin. (2006). General Education of American Universities-The Climbing of the American Mind. Beijing: Peking University Press.

[4] Wang Shouren. (2011). Some Thought on College English Teaching in China. Foreign Language Learning Theory and Practice. 1, 1-5.

[5] Zhu Xi. (2011). A Survey of English Majors' Reading of English and American Literary Masterpieces. Anhui Literature. 7 , $179-182$. 
Xunfeng Yin was born in the city of Tai'an, Shandong Province, China in 1976. In March 2006, she earned the degree of M. A. in English in Tianjin Foreign Studies University, China, majoring in the theory and practice of translation. She also is engaged in translation work besides the teaching of English intensive reading, listening and oral class.

As the guide teacher, Ms. Yin won the First Prize of Guide Teacher of the National College Students' English Contest in 2007, 2009 and 2010. 